\title{
News from the SETAC Europe Student Advisory Council (April 2013) - the 3rd Young Environmental Scientists (YES) meeting at the Jagiellonian University, Poland
}

\author{
Jochen P Zubrod ${ }^{1 *}$, Dragan M Jevtić ${ }^{2}$, Aupaki Michael Melato ${ }^{3}$, Dominic Englert ${ }^{1}$, Mirco Weill ${ }^{4}$ Erica K Brockmeier ${ }^{5}$, \\ Tilman Floehr ${ }^{6}$, Varja Knežević ${ }^{7}$, Annika Agatz ${ }^{8}$ and Markus Brinkmann ${ }^{6}$
}

\begin{abstract}
This article reports on the 3rd Young Environmental Scientists Meeting that was hosted from 11 to 13 February 2013 by the Institute of Environmental Sciences at the Jagiellonian University in Kraków, Poland. This student-only meeting under the theme of 'interdisciplinary discourse on current environmental challenges' was again organized by the Student Advisory Council of the Society of Environmental Toxicology and Chemistry Europe. An abstract book of the meeting is freely available as supplemental material of this article.
\end{abstract}

The Young Environmental Scientists (YES) Meetings are unique, student-only conferences aimed to help overcome some of the major issues young researchers have to cope with: receiving travel funding for scientific conferences, presenting research findings, and starting to build a scientific network. The 3rd YES Meeting (http:// www.sac-online.eu/yes2013/) took place from 11 to 13 February 2013 and was hosted by the Institute of Environmental Sciences at the Jagiellonian University in Kraków, Poland. This meeting was organized jointly by the Society of Environmental Toxicology and Chemistry (SETAC) Europe Student Advisory Council (SAC; chaired by Jochen Zubrod), the Local Organizing Committee (chaired by Dragan Jevtić), and the Scientific Committee (chaired by Michael Melato and Markus Brinkmann), with the aim of achieving a fruitful meeting on a high scientific level.

As with the two previous meetings in Landau [1] and Aachen [2], both in Germany, one of the main goals of the 3rd YES Meeting was to invite students from all over the world based solely on the scientific quality of their submitted abstracts and not on their geographical or

\footnotetext{
* Correspondence: zubrod@uni-landau.de

'Institute for Environmental Sciences, University of Koblenz-Landau,

Fortstraße 7, Landau D-76829, Germany

Full list of author information is available at the end of the article
}

financial limitations. To achieve this goal, participation in the YES Meeting was again free of charge and all student presenters received travel grants. This was only possible due to the remarkable financial support by our sponsors: SETAC (Europe, World, North America, and German Language Branch), universities (Institute of the Environmental Sciences of the Jagiellonian University and University of Koblenz-Landau), companies (BASF, Bayer CropScience, Dr. Knoell Consult, Evonik, Kawaska, Syngenta, and Waters), and a private sponsor (Mirco Bundschuh).

We received more than 145 abstracts in the fields of aquatic and terrestrial ecotoxicology, environmental risk assessment, effects and exposure modeling, environmental chemistry, life cycle assessment, nanoparticles, as well as omics and biomarkers from all over the world. After a thorough peer review by the Scientific Committee, 96 students from 27 countries were invited to give either one of 44 platform presentations (Table 1) and/or present a poster (all abstracts can be found in the program and abstract book published as Additional file 1 of this article; Figure 1). These contributions covered a wide array of topics and were generally of a very high scientific quality, which was judged by the participants and the senior scientists on site. This ensured the 
Table 1 Platform presentations given in one of the eight sessions during the 3rd YES Meeting (Krakow, Poland)

\begin{tabular}{ll}
\hline Session & Chairs \\
\hline Aquatic & D. Englert, T. Floehr, \\
ecotoxicology & V. Knežević, J. Zubrod
\end{tabular}

Ecological risk assessment and remediation techniques
M. Melato and J. Zubrod
Effects and exposure Jevtić and E. Zimmer modeling

Authors
Schmidt et al., Galway-Mayo
Institute of Technology, Ireland

Englert et al., University of Koblenz-Landau, Germany

Dimitrov et al., Wageningen University, The Netherlands

Rico et al., Wageningen University, The Netherlands

Peric et al., University of Barcelona, Spain

Biermans et al., Belgian Centre for Nuclear Research, Belgium

Knežević et al., University of Novi Sad, Serbia

Wolf et al., Goethe University Frankfurt, Germany

Tassou and Schulz, University of Koblenz-Landau, Germany

Di Paolo et al., Swiss Centre for Applied Ecotoxicology EawagEPFL, Switzerland

Vignet et al., IFREMER, France

Le Bihanic et al., University of Bordeaux, France

Nybom et al., University of Eastern Finland, Finland

Bluhm et al., RWTH Aachen University

Diepens et al., Wageningen University, The Netherlands

Peters et al., University of KoblenzLandau, Germany

Daniels et al., RWTH Aachen University, Germany

Qiu et al., Leiden University, The Netherlands

Zimmer et al., Vrije Universiteit Amsterdam, The Netherlands

Bui et al., RWTH Aachen University, Germany

Poma et al., IRSA-CNR Water Research Institute, Italy

Mueting and Lydy, Southern Illinois University, USA

Schür et al., RWTH Aachen University, Germany

Vierke et al., German Federal Environment Agency, Germany
Presentation

Evaluation of effects of the pharmaceuticals diclofenac and gemfibrozil on marine mussels (Mytilus spp.). Evidence for chronic sublethal effects on stress-response proteins

Varying wastewater dilution in receiving streams implications for stream ecosystem structure and function

Effects of the fungicide tebuconazole on fungal and bacterial communities in the sediment of outdoor freshwater microcosms

Direct and indirect effects of the antibiotic enrofloxacin on tropical freshwater microcosms

Aquatic and cellular toxicity of ionic liquids and their potential biodegradability in water

Biological effects induced in Arabidopsis thaliana after aquatic exposure to radioactive contaminants

Sensitivity and recovery potential of Lemna minor after exposure to herbicide mixtures

When predictions go wrong: mixture toxicity of a repellent and a pyrethroid on aquatic invertebrates

Environmentally-relevant tebufenozide concentrations affect reproduction in the freshwater midge Chironomus riparius in a chronic toxicity test

Can the sensitivity and predictive potential of zebrafish early life stage (ELS) tests be improved by additional endpoints and chemical analysis?

Long-term effects of an early and continuous exposure to PAHs on zebrafish behavioral responses

Comparative effects of three $\mathrm{PAH}$ fractions from light and heavy crude oils and from a PAH-contaminated sediment on Oryzias latipes Japanese medaka early life stages

Responses of Lumbriculus variegatus to activated carbon amendments

Potential biofuels in an ecotoxicological investigation

Optimizing sediment conditions for macrophyte testing in the context of prospective risk assessment

Effects of anthropogenic pollutants on ecosystem functions in freshwater bodies - a review

Comparison of mechanistic models and standardized regression analyses to describe toxic effects in ecotoxicology

Predicting copper toxicity in different ecotypes of earthworms based on biotic ligand model concept

Interaction between food and toxicant leads to hormesis in the pond snail Lymnaea stagnalis

Food dependent life cycle parameters of Nitocra spinipes implications to extrapolate effects to population level

Novel brominated flame retardants (NBFRS) contamination in sediments from Lake Maggiore basin

Fate of a transgenic insecticidal protein, a pyrethroid insecticide, and neonicotinoid insecticides within a maize agricultural ecosystem

Kinetics for membrane dialysis extraction of pyrene, phenanthrene and chrysene from n-hexane and cow milk

Fate of short chain perfluorinated carboxylic and sulfonic acids in a water-saturated sediment column investigated under near-natural conditions 
Table 1 Platform presentations given in one of the eight sessions during the 3rd YES Meeting (Krakow, Poland) (Continued)

Life Cycle Assessment Due to withdrawals included in terrestrial ecotoxicology session

Nanoparticles

$\begin{array}{ll}\text { Omics and } & \text { M. Brinkmann and } \\ \text { biomarkers } & \text { E. Brockmeier }\end{array}$

$\begin{array}{ll}\text { Terrestrial } & \text { H. Azarbard and } \\ \text { ecotoxicology } & \text { D. Chmolowska }\end{array}$

Ochiai et al., Ehime University, Japan

Kurtz et al., University of KoblenzLandau, Germany

Cesar et al., Fluminense Federal University Niterói, Brazil

Torres, Eawag, Swiss Federal Institute of Aquatic Science and Technology, Switzerland

Rieckhof and Günther, TU Dresden, Germany

Stevenson et al., Ecology, Evolution and Marine Biology, University of California, USA

Ribas et al., Federal University of Paraná, Brazil

Seitz et al., University of KoblenzLandau

Ramskov et al., Roskilde University, Nanoparticle shape affects bioaccumulation and toxicity in Denmark

Walter et al., ECT Oekotoxikologie $\mathrm{GmbH}$, Germany

Burkart et al., TU Dresden, Germany

Waalewijn-Kool et al., VU University, The Netherlands

Sovová et al., Institute of Chemical Natural and artificial organic substances alter algal toxicity Technology, Prague, Czech Republic

Brockmeier et al., University of Florida, USA

Rock et al., Helmholtz Zentrum München, Germany

Ogunkeyede et al., University of Nottingham, UK

Mikowska and ŚwiergoszKowalewska, Jagiellonian University, Poland

Musso et al., University of Aveiro, Portugal

Pariyar and Burkhardt, University of Bonn, Germany

Srećkovićet al., University of Novi Sad
Transfer and distribution of hydroxylated polychlorinated biphenyls (OH-PCBs) in the brain of finless porpoises (Neophocaena phocaenoides)

Effects of olive oil production wastewater on soil arthropods in two different cultivation scenarios in Israel and Palestine

Distribution of mercury, copper and zinc in soils and fluvial sediments from an abandoned gold mining area in southern Minas Gerais state, Brazil

Simplify your sediment pore water analysis

Carbon footprint for the joint production of a wood-based product and its by-product - a case study

The effect of titanium dioxide nanoparticles on freshwater organisms

Toxic effects of lead and nanoparticles mixed in anterior kidney cell cultures from freshwater fish

Product and size specific ecotoxicity of titanium dioxide nanoparticles to Daphnia magna a deposit-feeding snail

Acute and chronic effects of magnetite-based nanocomposites on invertebrates (Hyalella azteca and Chironomus riparius) and zebrafish embryos (Danio rerio)

A novel method for the determination of effects of nanomaterials on organisms related to wastewater treatment plants

The effect of $\mathrm{pH}$ on the toxicity of $\mathrm{ZnO}$ nanoparticles to Folsomia candida in amended field soil

of nano $\mathrm{CeO}_{2}$

Evaluating the impacts of androgen exposure on eastern mosquitofish (Gambusia holbrooki) global hepatic gene expression patterns using a custom microarray

Catecholamines and other biomarkers in stressed and nonstressed amphipods

The characterisation of crude oil and oil contaminated soil from the Niger Delta by catalytic hydropyrolysis

Molecular biomarkers as indicators of bank vole populations' response to metal pollution

Invasive vs. native grasses in Cerrado (Brazilian savanna): physiological and morphological responses to a mosaic of environmental conditions

Effects of aerosol particles on crop plants

Extremely low frequency $(50 \mathrm{~Hz})$ electromagnetic field exposure alters nutritive stress response in Eisenia fetida (Lumbricidae) 


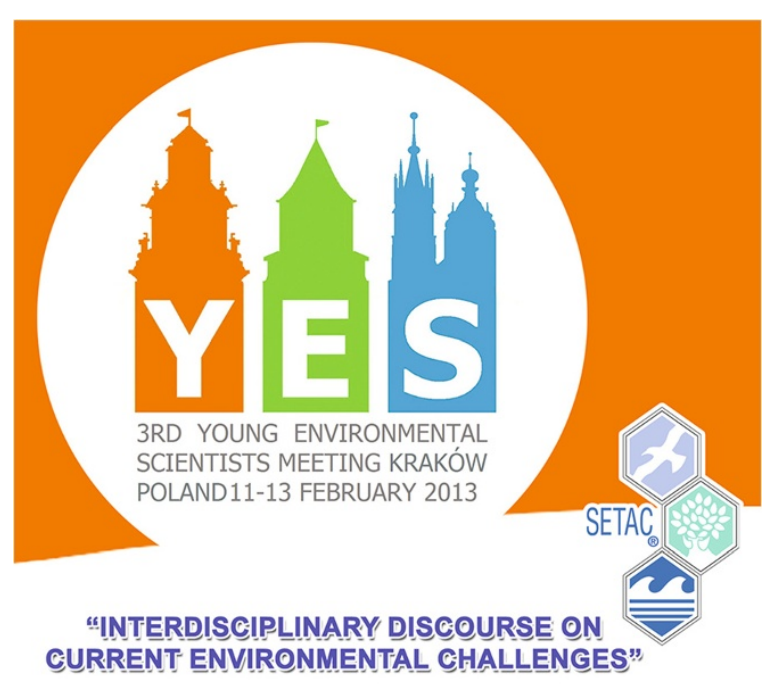

\section{1 - 13 February 2013}

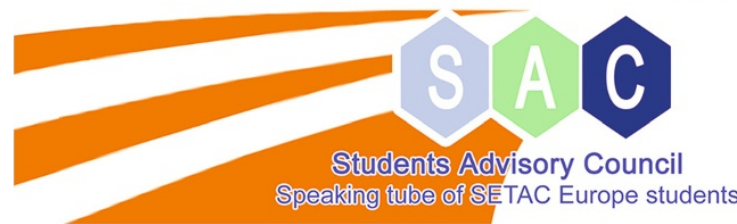

Figure 1 The entire program and abstract book is published as Additional file 1 to this article.

compliance with both the meeting's and SETAC's mottos of 'interdisciplinary discourse on current environmental challenges' and 'environmental quality through science'. Participants used the time after the talks and during the poster social for engaging in discussions and to get to know each other (Figure 2).
Students also participated in a soft-skills training in scientific networking organized by Valery Forbes of the University of Nebraska-Lincoln. During her highly interactive workshop 'Being remembered for the right reasons', the participants learned how to approach senior scientists and the basics of scientific small talk. The

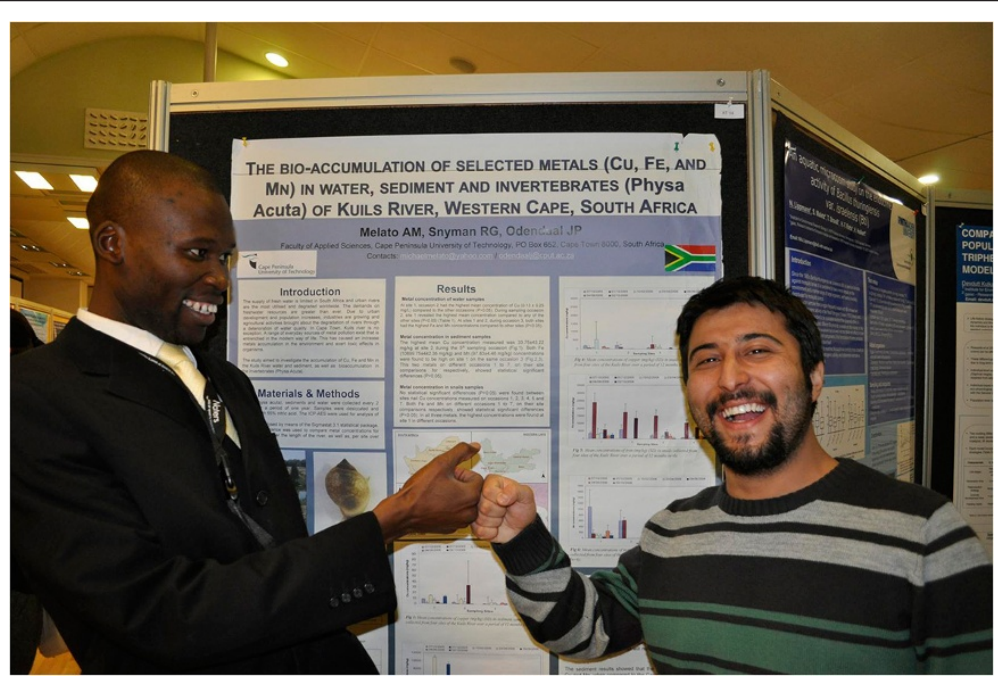

Figure 2 Successful networking during the poster social (photograph taken by Zmnako Awrahman). 
overwhelmingly positive feedback by the workshop participants clearly indicates that the soft-skills course was an effective learning tool. Three career talks - given by Sue Martina Starke (UBA - German Federal Environment Agency), Matthias Bergtold (BASF, Germany), and Alistair Boxall (University of York, UK) - provided the participants with helpful insights such as necessary skills and qualifications as well as opportunities and challenges of careers in government, business, and academia, the three sectors represented by SETAC. As a supplement to the career talks, two of our partners (BASF and UBA) additionally presented their company/institution in the job corner. The participants used this opportunity to get in contact with these potential future employers.

From the feedback of the senior scientists on site as well as the participants - results from an online questionnaire were positive in all assessed categories - we believe that the 3rd YES Meeting was again a unique opportunity for the participants to become familiar with routines associated with a scientific career and a good starting point to build a wide scientific network. We thus want to thank all of our supporters and hope that in 2015 we can report in this journal about the 4th YES Meeting.

\section{Additional file}

Additional file 1: The 3rd Young Environmental Scientists Meeting

February 2013, Krakow, Poland. Program and abstract book.

\section{Competing interests}

The authors declare that they have no competing interests.

\section{Authors' contributions}

JPZ, DMJ, AMM, DE, MW, EKB, TF, VK, AA, and MB are members of the SAC or its North American counterpart (NASAC) and the Scientific Committee of the meeting and have essentially participated in the organization and conduct of the meeting. All authors have read and approved the final manuscript.

\section{Acknowledgments}

The SAC is indebted to all sponsors, the Local Organizing and the Scientific Committee, the meeting participants, Sue Martina, Alistair, Matthias, and especially Valery as well as all other persons and institutions that supported the organization and conduct of the meeting. Furthermore, we thank ESEU for providing this platform.

\section{Author details}

${ }^{1}$ Institute for Environmental Sciences, University of Koblenz-Landau, Fortstraße 7, Landau D-76829, Germany. ${ }^{2}$ Ecotoxicology and Stress Ecology Group, Jagiellonian University, Gronostajowa 7, Kraków 30-387, Poland. ${ }^{3}$ Faculty of Applied Science, Cape Peninsula University of Technology, PO Box 652, Cape Town 8000, South Africa. ${ }^{4} \mathrm{ECT}$ Oekotoxikologie GmbH, Boettgerstraße 2-14, Floersheim a.M D-65439, Germany. ${ }^{5}$ Center for Environmental and Human Toxicology, University of Florida, 2187 Mowry Road, Gainesville, FL 32611, USA. ${ }^{6}$ Department of Ecosystem Analysis, Institute for Environmental Research, RWTH Aachen University, Worringerweg 1, Aachen D-52074, Germany. ${ }^{7}$ Faculty of Sciences, University of Novi Sad, Trg Dositeja Obradovića 3, Novi Sad 21 000, Serbia. ${ }^{8}$ Environment Department, University of York, Heslington, York YO10 5DD, UK.

Received: 22 May 2013 Accepted: 27 May 2013

Published: 28 June 2013

\section{References}

1. Bundschuh M, Dabrunz A, Bollmohr S, Brinkmann M, Caduff M, Gomez-Eyles J, Kienle C, Melato M, Patrick-Iwuanyanwu K, Van Hoecke K, Seiler T-B, Brooks A: 1st Young Environmental Scientists (YES) Meeting - new challenges in environmental sciences. Environ Sci Pollut Res 2009, 16:479-481.

2. Brinkmann M, Kaiser D, Peddinghaus S, Berens ML, Braunig J, Galic N, Bundschuh M, Zubrod JP, Dabrunz A, Liu T, Melato M, Mieiro C, Sdepanian S, Westman O, Kimmel S, Seiler TB: The Second Young Environmental Scientist (YES) Meeting 2011 at RWTH Aachen University environmental challenges in a changing world. Europe: Environ Sci 2011, 23:29.

\section{doi:10.1186/2190-4715-25-16}

Cite this article as: Zubrod et al:: News from the SETAC Europe Student Advisory Council (April 2013) - the 3rd Young Environmental Scientists (YES) meeting at the Jagiellonian University, Poland. Environmental Sciences Europe 2013 25:16.

\section{Submit your manuscript to a SpringerOpen ${ }^{\odot}$ journal and benefit from:}

- Convenient online submission

- Rigorous peer review

- Immediate publication on acceptance

- Open access: articles freely available online

- High visibility within the field

- Retaining the copyright to your article

Submit your next manuscript at springeropen.com 